\title{
Hate to Burst Your Balloon: Successful REBOA Use Takes More Than a Course
}

\author{
Christina M Theodorou MD'1, Edgardo S Salcedo MD' ${ }^{1}$, Joseph J DuBose MD² \\ and Joseph M Galante MD ${ }^{1}$ \\ 'Department of Surgery, University of California Davis Medical Center, Sacramento, California, USA \\ 2Department of Surgery, University of Maryland School of Medicine, Baltimore, Maryland, USA
}

\begin{abstract}
Background: Resuscitative endovascular balloon occlusion of the aorta (REBOA) is emerging as a viable intervention for hemorrhagic shock. Training surgeons to place the device is only part of the process. We hypothesize that implementation challenges extend beyond surgical skills training and initial REBOA use should not be expected to mirror published success.

Methods: All REBOA placements from January 2016 to February 2017 at a level 1 trauma center were reviewed for opportunities for improvement. From September 2016 to February 2017, all patients meeting highest trauma activation criteria were reviewed against our REBOA algorithm to identify patients meeting criteria for REBOA placement but not undergoing the procedure.

Results: REBOA was introduced at our institution in September 2015, with the first placement in January 2016. Trauma surgery, emergency department, and operating room staff underwent training. Nine patients had REBOA placed with six survivors. One patient underwent an unsuccessful REBOA attempt and died. Four patients had complications from REBOA. Eight additional patients met indications but did not undergo REBOA.

Conclusions: Successful REBOA use requires more than teaching surgeons indications and techniques. For a successful REBOA program, system factors must be addressed. System processes must ensure equipment and procedures are standardized and familiar to all involved. Complications should be expected.
\end{abstract}

Keywords REBOA; Implementation; Algorithm; Trauma

Received: 20 November 2019; Accepted: 27 March 2020

\section{INTRODUCTION}

Resuscitative endovascular balloon occlusion of the aorta (REBOA) is a minimally invasive intervention for patients in hemorrhagic shock. Trauma centers are increasingly adopting REBOA use in initial resuscitation and during operative interventions for critically injured patients. It is currently being used at more than 300 centers across the United States. There have been

\section{Corresponding author:}

Christina M Theodorou, MD, 2335 Stockton Blvd Room 5107, Sacramento, CA 95817, USA.

Email: ctheodorou@ucdavis.edu

Presentation: This work was presented as a quickshot poster presentation at the 2019 Pan-American Endovascular Resuscitation and Trauma Management Symposium.

(C) 2020 CC BY 4.0 - in cooperation with Depts. of Cardiothoracic/ Vascular Surgery, General Surgery and Anesthesia, Örebro University Hospital and Örebro University, Sweden multiple published reports of successful REBOA use and it is rapidly gaining popularity as an intervention in the unstable patient [1-9].

As with any new technique, there will be a learning curve. Although placement of the device is relatively straightforward and there are training courses, such as the American College of Surgeons Basic Endovascular Skills for Trauma (BEST) course, the Endovascular Skills for Trauma and Resuscitative Surgery course, or the Endovascular Resuscitation and Trauma Management (EVTM) workshops available for surgeons to learn the technique [10-12], implementation of a REBOA program requires the coordination and training of surgical faculty, resident trainees, emergency department (ED) staff, ancillary staff including nurses, ED department and operating room (OR) technicians, and hospital administration to be successful. Given the complexity of instituting a successful program, we posit that there will be a learning curve that is not simply explained by attending surgeons gaining experience in REBOA placement [13-15]. Despite the growing popularity of REBOA, 
initial REBOA implementation should not be expected to mirror published success.

We hypothesize that successful REBOA use requires more than technical skills courses, and that in the early phases of a REBOA program, patients will have REBOA placed outside of the institutional algorithms and patients who may benefit from the procedure will be missed. The challenges of implementation extend beyond the clinical skillset of trauma surgeons and will require the preparedness of other healthcare providers involved in the care of injured patients, requiring a systems-level approach.

\section{METHODS}

After approval by our Institutional Review Board (IRB\# 1102164-1), all REBOA placements from January 2016 to February 2017 at a level 1 trauma center were reviewed against our institution's REBOA algorithm (Figure 1) to analyze protocol adherence. We then queried all patients who met the highest trauma activation criteria based on our institution's triage protocol from September 2016 to February 2017. From these patients, we identified all patients who met criteria for REBOA placement by the algorithm shown in Figure 1 to identify potential REBOA-eligible patients who did not undergo the procedure. We chose to perform this analysis of all trauma activations nine months after REBOA had been implemented at our institution to allow for a grace period for training surgeons and ED physicians and institutional preparation. Adult patients aged 18-90 years of age were included.

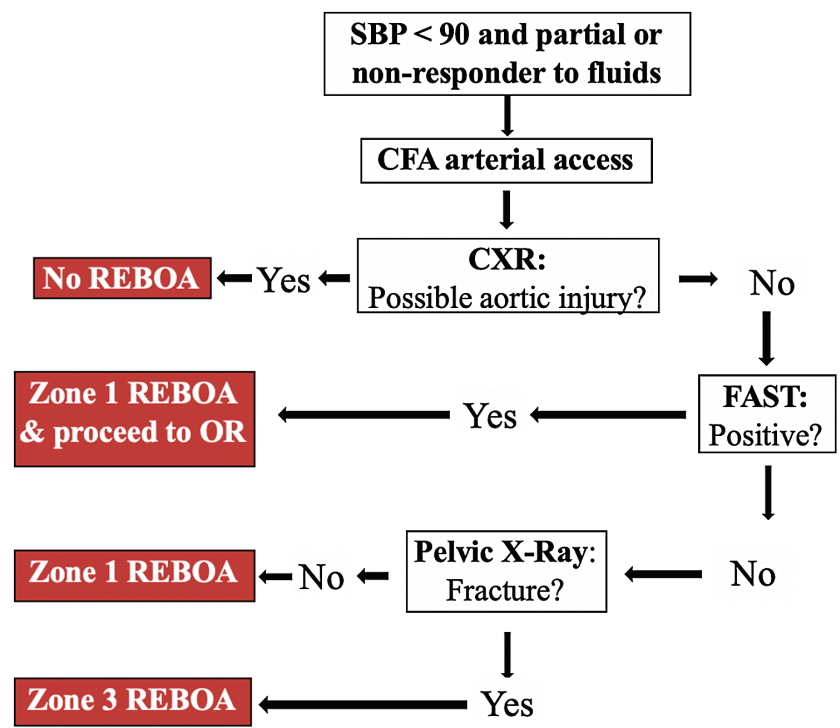

Figure 1 REBOA algorithm. Resuscitative endovascular balloon occlusion of the aorta (REBOA) algorithm SBP: systolic blood pressure; CFA: common femoral artery; CXR: chest X-ray; FAST: Focused Assessment with Sonography in Trauma; OR: operating room. Zone 1 refers to the aorta between the left subclavian artery and the celiac axis. Zone 3 refers to the infrarenal aorta to the aortic bifurcation.
In determining which patients met REBOA indications but did not undergo REBOA, several exclusion criteria were used (Table 1). Patients with penetrating thoracic trauma were excluded because REBOA is potentially contraindicated in patients with suspected or known thoracic great vessel injury. Patients with isolated penetrating head trauma were excluded as the effect of aortic occlusion on traumatic brain injuries is unknown at this time [16]. Patients whose major trauma was burn or blast injury were excluded. Patients who did not have a chest radiograph (CXR), focused assessment with sonography for trauma (FAST) scan, and pelvis radiograph were excluded as these are part of the institutional algorithm for REBOA placement.

All quality improvement (QI) discussions were reviewed for opportunities for improvement. The QI discussions informed the development of a framework of focus areas to guide the successful implementation of a REBOA program at an institution. Via chart review we obtained demographic data, vital signs, mechanism of injury, injury list, Injury Severity Score, Abbreviated Injury Scale, outcomes, and mortality information. For patients who underwent REBOA, we recorded the type of REBOA catheter used, method of vascular access (percutaneous or via cut-down), zone of REBOA deployment, whether an angiogram was performed, and any complications related to REBOA.

\section{Ethical Approval and Informed Consent}

Ethical approval was given by our Institutional Review Board (IRB\# 1102164-1). A waiver of written informed consent was obtained for this study.

\section{RESULTS}

REBOA was introduced at our institution in September 2015, with the first device placed in January 2016.

Table 1 Exclusion criteria.

\begin{tabular}{l} 
Exclusion Criteria \\
\hline - Age $<18$ or $>90$ years old \\
- Prisoners \\
- Burn or blast injury \\
- Isolated head or neck injury \\
- Penetrating thoracic trauma \\
- Deceased on arrival \\
- Normotension (Systolic blood pressure (SBP) $>90)$ \\
- Transient hypotension responsive to fluids \\
- Alternative diagnosis other than trauma \\
- Missing imaging (CXR, PXR, FAST)
\end{tabular}

CXR: chest X-ray; PXR: pelvis X-ray; FAST: Focused Assessment with Sonography for Trauma 
Table 2 Patient characteristics.

\begin{tabular}{lll}
\hline \multicolumn{1}{c}{ Patient Characteristics } & \multicolumn{1}{c}{$\begin{array}{c}\text { REBOA } \\
(n=9)\end{array}$} & $\begin{array}{c}\text { REBOA- } \\
\text { Eligible } \\
(n=8)\end{array}$ \\
\hline $\begin{array}{l}\text { Age, years: median (IQR) } \\
\text { Male: } n \text { (\%) }\end{array}$ & $\begin{array}{l}41(27-48) \\
9(100)\end{array}$ & $\begin{array}{l}4(25-54) \\
\text { Mechanism of injury: } n(\%)\end{array}$ \\
- Blunt & $5(55.6)$ & $7(88)$ \\
- Penetrating & $4(44.4)$ & $1(12)$ \\
CPR: $n$ (\%) & & \\
- Initiated prior to arrival & $1(11.1)$ & $0(0)$ \\
- Ongoing at arrival & $0(0)$ & $0(0)$ \\
- Initiated in ED & $2(22.2)$ & $1(12)$ \\
Injury Severity Score: median (IQR) & $50(25-57)$ & $39.5(28-59.3)$ \\
\hline
\end{tabular}

IQR: Interquartile range; CPR: cardiopulmonary resuscitation; ED: emergency department

All 12 trauma faculty were trained via an institutional REBOA course. ED and OR nursing staff underwent in-service training. The REBOA kit was located in the ED trauma rooms as well as in the OR supply area.

\section{REBOA Placements}

A total of nine patients underwent REBOA placement in the first year at our institution. Baseline characteristics are shown in Table 2 compared with REBOA-eligible patients. Detailed information on each REBOA case is shown in Table 3. The majority $(66.7 \%)$ underwent Zone 1 deployment, with two undergoing Zone 2 placement and one having Zone 3 placement. Most REBOA catheters were placed in the OR $(66.7 \%)$, either at the start of the case in a hypotensive patient or intraoperatively due to ongoing bleeding to obtain temporary hemostasis. Four patients $(44.4 \%)$ sustained REBOA-related complications (Table 4). Six patients $(66.7 \%)$ who had REBOA placed survived to hospital discharge (Table 5); the remaining three died in the ICU (Table 6). One additional patient sustained multiple gunshot wounds to the chest and arrived under cardiopulmonary resuscitation (CPR). The patient underwent thoracotomy and attempted REBOA placement; however, femoral access could not be obtained despite the use of ultrasound bilaterally. The patient died in the ED. Consideration should be given to performing femoral artery cutdown in patients in whom percutaneous access is difficult.

When analyzed per our REBOA algorithm (Figure 1), only one placement, a Zone 3 placement for pelvic fractures with hemodynamic instability, was placed in accordance with the algorithm. The remaining eight REBOAs were placed outside of our algorithm. Of these, four were determined to be appropriate REBOA placements: two of the patients met criteria for Zone 1 placement in the ED but did not undergo REBOA placement until they were transported to the OR, and an additional two patients had REBOA placed intraoperatively for bleeding, and had not been hypotensive in the ED. Two patients had REBOA placed despite widened mediastinum on CXR, a sign of possible aortic or great vessel injury, which is a contraindication in our algorithm. Two patients had REBOA placed while undergoing CPR without prior imaging and thus could not be evaluated against our algorithm.

\section{REBOA Complications}

In total, four of the nine REBOA patients experienced REBOA-related complications (Table 4). In one patient, the REBOA catheter was inserted via the left common femoral artery and the balloon was inflated below the aortic bifurcation. The patient had a rupture of the common iliac artery on the ipsilateral side. This patient had severe pelvic fractures, and additionally had an injury to the contralateral internal iliac artery. On multidisciplinary review, it was not clear if the left common iliac artery injury was due to the patient's extensive pelvic fractures or due to the inflation of the REBOA balloon, but iatrogenic injury must be considered a possible complication in this patient. This patient succumbed to multisystem organ failure 19 days after admission.

In two patients, femoral artery thrombosis occurred. One patient had a 14 French sheath in the common femoral artery for over 60 minutes without anticoagulation due to uncontrollable hemorrhage. Vascular surgery was consulted intraoperatively to perform an aortic angiogram to evaluate for a potential aortic source of the hemorrhage and chose to perform a thrombectomy at the time of closure of the access site at the conclusion of the case. In the second patient, access was obtained via the right femoral artery. Aortic occlusion occurred for $19 \mathrm{~min}$, and the sheath was removed at the end of the case. The distal femoral artery had some vasospasm but maintained biphasic flow. A completion angiogram was unable to be performed due to patient instability. However, that evening, he had diminished pulses to the right lower extremity and imaging demonstrated superficial femoral artery occlusion and he underwent thrombectomy with no further vascular complications.

The fourth patient was transferred to our institution with known celiac axis aortic injury due to a gunshot wound. Given his presentation, he proceeded immediately to the angiography-equipped OR and underwent trauma surgery and vascular surgery. There were absent bilateral femoral pulses noted at the start of the case. As the trauma surgery team performed a laparotomy, the vascular surgery team obtained percutaneous access of the right common femoral artery and placed a 7 French sheath through which the REBOA catheter was introduced. As the surgical teams worked to expose and mobilize the aortic injury, the patient became hypotensive and 
Table 3 Detailed information on REBOA patients.

\begin{tabular}{|c|c|c|c|c|c|c|c|}
\hline Patient & Mechanism & Initial Vitals & Imaging & REBOA Data & Injuries & Notes & Died \\
\hline $1^{*}$ & $\begin{array}{l}\text { Ped. vs. } \\
\text { auto }\end{array}$ & $\begin{array}{l}\text { HR: } 75 \\
\text { BP: } 83 / 69\end{array}$ & $\begin{array}{l}\text { CXR: Neg } \\
\text { FAST: Neg } \\
\text { PXR: Pos }\end{array}$ & $\begin{array}{l}\text { Placed: ED } \\
\text { Zone: } 3 \\
\text { Access: percutaneous } \\
\text { Sheath: unknown } \\
\text { AO time: unknown }\end{array}$ & $\begin{array}{l}\text { Pelvic fractures, } \\
\text { R IIA injury, } \\
\text { L CIA injury }\end{array}$ & & Yes \\
\hline $2^{*}$ & $\begin{array}{l}\text { Crush injury } \\
\text { to chest }\end{array}$ & CPR & $\begin{array}{l}\text { CXR: N/A } \\
\text { FAST: Neg } \\
\text { PXR: N/A }\end{array}$ & $\begin{array}{l}\text { Placed: ED } \\
\text { Zone: } 1 \\
\text { Access: percutaneous } \\
\text { Sheath: } 14 \mathrm{Fr} \\
\text { AO time: } 60 \text { min }\end{array}$ & Sternal disruption & & Yes \\
\hline 3 & $\begin{array}{l}\text { Ped. vs. } \\
\text { auto }\end{array}$ & $\begin{array}{l}\text { HR: } 78 \\
\text { BP: } 75 / 59\end{array}$ & $\begin{array}{l}\text { CXR: POS } \\
\text { FAST: POS } \\
\text { PXR: POS }\end{array}$ & $\begin{array}{l}\text { Placed: ED } \\
\text { Zone: } 1 \\
\text { Access: percutaneous } \\
\text { Sheath: } 7 \text { Fr } \\
\text { AO time: not inflated }\end{array}$ & $\begin{array}{l}\text { Grade } 3 \text { hepatic } \\
\text { laceration, grade } 3 \\
\text { splenic laceration, } \\
\text { grade } 4 \text { renal } \\
\text { laceration, pelvic } \\
\text { fractures }\end{array}$ & $\begin{array}{l}\text { CXR with widened } \\
\text { mediastinum } \\
\text { but chest CT } \\
\text { without vascular } \\
\text { injury }\end{array}$ & Yes \\
\hline 4 & MCC & $\begin{array}{l}\text { HR: } 131 \\
\text { BP: } 112 / 57\end{array}$ & $\begin{array}{l}\text { CXR: Neg } \\
\text { FAST: Pos } \\
\text { PXR: N/A }\end{array}$ & $\begin{array}{l}\text { Placed: OR } \\
\text { Zone: } 2 \\
\text { Access: percutaneous } \\
\text { Sheath: } 7 \mathrm{Fr} \\
\text { AO time: not inflated }\end{array}$ & $\begin{array}{l}\text { Grade } 5 \text { splenic } \\
\text { laceration, grade } 5 \\
\text { renal laceration }\end{array}$ & $\begin{array}{l}\text { Met REBOA } \\
\text { indications in ED } \\
\text { Placed intra- } \\
\text { operatively for } \\
\text { expanding } \\
\text { Zone } 2 \mathrm{RPH}\end{array}$ & No \\
\hline 5 & $\begin{array}{l}\text { Torso stab } \\
\text { wound }\end{array}$ & $\begin{array}{l}\text { HR: } 103 \\
\text { BP: } 111 / 62\end{array}$ & $\begin{array}{l}\text { CXR: Neg } \\
\text { FAST: N/A } \\
\text { PXR: N/A }\end{array}$ & $\begin{array}{l}\text { Placed: OR } \\
\text { Zone: } 2 \\
\text { Access: percutaneous } \\
\text { Sheath: } 8 \mathrm{Fr} \\
\text { AO time: } 12 \text { min }\end{array}$ & $\begin{array}{l}\text { Grade } 3 \text { kidney } \\
\text { laceration, Grade } 1 \\
\text { splenic laceration }\end{array}$ & $\begin{array}{l}\text { Placed intra- } \\
\text { operatively for } \\
\text { bleeding from } \\
\text { renal hilum }\end{array}$ & No \\
\hline 6 & GSW chest & $\begin{array}{l}\text { HR: } 107 \\
\text { BP: } 138 / 84\end{array}$ & $\begin{array}{l}\text { CXR: Neg } \\
\text { FAST: Pos } \\
\text { PXR: N/A }\end{array}$ & $\begin{array}{l}\text { Placed: OR } \\
\text { Zone: } 1 \\
\text { Access: percutaneous } \\
\text { Sheath: unknown } \\
\text { AO time: unknown }\end{array}$ & $\begin{array}{l}\text { Gastric injury, Grade } 5 \\
\text { kidney laceration, } \\
\text { splenic laceration }\end{array}$ & $\begin{array}{l}\text { Placed intra- } \\
\text { operatively for } \\
\text { bleeding }\end{array}$ & No \\
\hline $7^{*}$ & GSW chest & $\begin{array}{l}\text { HR: } 140 \\
\text { BP: } 123 / 72\end{array}$ & $\begin{array}{l}\text { CXR: Neg } \\
\text { FAST: Pos } \\
\text { PXR: Neg }\end{array}$ & $\begin{array}{l}\text { Placed: OR } \\
\text { Zone: } 1 \\
\text { Access: cut down } \\
\text { Sheath: unknown } \\
\text { AO time: } 19 \text { min }\end{array}$ & $\begin{array}{l}\text { Gastric injury, } \\
\text { splenic laceration, } \\
\text { diaphragm injury, } \\
\text { lung laceration }\end{array}$ & $\begin{array}{l}\text { Placed intra- } \\
\text { operatively for } \\
\text { bleeding }\end{array}$ & No \\
\hline 8 & Ped. vs auto & CPR & $\begin{array}{l}\text { CXR: N/A } \\
\text { FAST: N/A } \\
\text { PXR: N/A }\end{array}$ & $\begin{array}{l}\text { Placed: OR } \\
\text { Zone: } 1 \\
\text { Access: cut down } \\
\text { Sheath: } 12 \mathrm{Fr} \\
\text { AO time: unknown }\end{array}$ & $\begin{array}{l}\text { Cardiac injury, } \\
\text { stellate liver } \\
\text { laceration }\end{array}$ & ED thoracotomy & Yes \\
\hline $9^{*}$ & GSW chest & $\begin{array}{l}\text { HR: } 130 \\
\text { BP: 109/97 }\end{array}$ & $\begin{array}{l}\text { CXR: Pos } \\
\text { FAST: N/A } \\
\text { PXR: Neg }\end{array}$ & $\begin{array}{l}\text { Placed: OR } \\
\text { Zone: } 1 \\
\text { Access: percutaneous } \\
\text { Sheath: } 7 \text { Fr } \\
\text { AO time: } 60 \text { min }\end{array}$ & $\begin{array}{l}\text { Supraceliac aortic } \\
\text { transection }\end{array}$ & $\begin{array}{l}\text { CXR: widened } \\
\text { mediastinum } \\
\text { REBOA placed } \\
\text { intra-operatively } \\
\text { proximal to known } \\
\text { aortic injury }\end{array}$ & No \\
\hline
\end{tabular}

Ped. vs auto: pedestrian vs. automobile; MCC: motorcycle crash; GSW: gunshot wound; HR: heart rate; BP: blood pressure; CXR: chest X-ray; FAST: Focused Assessment with Sonography in Trauma; PXR: pelvic X-ray; ED: emergency department; OR: operating room; AO: aortic occlusion; CT: computed tomography; RPH: retroperitoneal hematoma; R IIA: right internal iliac artery; L CIA: left common iliac artery; Fr: French.

* Sustained complication, see Table 4 for detailed information. 
Table 4 REBOA-related complications.

\begin{tabular}{lll}
\hline Patient & \multicolumn{1}{c}{ Complications } & \multicolumn{1}{c}{ Management } \\
\hline 1 & $\begin{array}{l}\text { Left common iliac artery } \\
\text { rupture }\end{array}$ & Stent placement \\
2 & $\begin{array}{l}\text { Right common femoral } \\
\text { artery thrombus }\end{array}$ & Thrombectomy \\
7 & $\begin{array}{l}\text { Right superficial femoral } \\
\text { artery thrombus }\end{array}$ & Thrombectomy \\
9 & $\begin{array}{l}\text { Right external iliac artery, } \\
\text { popliteal, tibial thrombosis }\end{array}$ & $\begin{array}{l}\text { Right iliofemoral, popliteal, } \\
\text { tibial thrombectomy; right }\end{array}$ \\
& $\begin{array}{ll}\text { Left popliteal, tibial } \\
\text { thrombosis }\end{array}$ & Left popliteal, tibial throm- \\
& & bectomy \\
\hline
\end{tabular}

Table 5 Comparison of survivors.

\begin{tabular}{lll}
\hline & \multicolumn{1}{c}{$\begin{array}{c}\text { REBOA Survivors } \\
n=6 \text { of } 9\end{array}$} & \multicolumn{1}{c}{$\begin{array}{c}\text { REBOA-eligible } \\
\text { Survivors } \\
n=6 \text { of } 8\end{array}$} \\
\hline Survivors: \% (n) & $66.7(6)$ & $75(6)$ \\
Age: median (IQR) & $35.3(24.7-45.2)$ & $33(23-49)$ \\
Blunt: \% ( $n$ ) & $33(2)$ & $83(5)$ \\
ISS: median (IQR) & $30.5(25-46.5)$ & $39.3(30.3-54)$ \\
\hline
\end{tabular}

IQR: Interquartile range; ISS: Injury Severity Score

Table 6 Comparison of non-survivors.

\begin{tabular}{lll}
\hline & \multicolumn{1}{c}{$\begin{array}{c}\text { REBOA Deaths } \\
n=3 \text { of } 9\end{array}$} & \multicolumn{1}{c}{$\begin{array}{c}\text { REBOA-eligible } \\
\text { Deaths } \\
n=2 \text { of } 8\end{array}$} \\
\hline All deaths: \% (n) & $33.3(3)$ & $25(2)$ \\
Died in ED: \% (n) & $0(0)$ & $0(0)$ \\
Died in OR: \% (n) & $33.3(1)$ & $0(0)$ \\
Died in ICU: \% (n) & $66.7(2)$ & $100(2)$ \\
Age: median (IQR) & $53(47.5-56)$ & $64(59.5-68.5)$ \\
Blunt trauma: \% (n) & $100(3)$ & $100(2)$ \\
ISS: median (IQR) & $75(62.5-75)$ & $42.5(26.3-58.8)$ \\
\hline
\end{tabular}

ED: emergency department; OR: operating room; ICU: intensive care unit; IQR: interquartile range; ISS: Injury Severity Score

the REBOA balloon was inflated in Zone 1, proximal to the known aortic injury. At this point repair of the complex aortic injury proceeded and the REBOA was exchanged for an aortic cross-clamp. The combined aortic occlusion time for both was $60 \mathrm{~min}$. Lower extremity pulses were not detectable at the conclusion of the case, and duplex ultrasound revealed no flow beyond the popliteal artery. Angiography was not done at this time due to concern for contrast load from pre-operative imaging, prolonged warm ischemia time to the kidneys, and overall coagulopathy. The sheath was left in place. On evaluation on post-operative day 1, bilateral feet were cool, pulseless, and mottled and duplex ultrasound showed right iliac, superficial femoral, popliteal, and tibial artery thrombosis, as well as left popliteal and tibial thrombosis. He underwent bilateral angiogram, thrombectomy, and right leg fasciotomies. However, due to ongoing ischemia, a right above knee amputation was performed on post-operative day 12 .

\section{REBOA-Eligible Patients}

A total of eight patients were found to have met indications for REBOA placement but did not undergo the procedure (Figure 2). All of these patients underwent exploratory laparotomy following initial resuscitation in the ED. Two of these patients $(25 \%)$ died. The demographic breakdown of these patients is shown in Table 2. In total, six of these patients met indications for Zone 1 REBOA placement and the remaining two met criteria for Zone 3 placement. Of the patients who met the criteria for Zone 1 placement, injuries included retroperitoneal hematoma, multiple high-grade solid organ injuries, and external iliac artery and vein injury. The two patients who died did not have injuries for which REBOA would provide hemorrhage control. In one patient, a para-duodenal retroperitoneal hematoma was noted intra-operatively but did not appear to be the cause of his hemodynamic instability. The second patient had an avulsion of the left ventricle which was the likely cause of death. Half of the hypotensive patients identified did not have other contraindications to REBOA but were missing one or more of the imaging modalities in our REBOA algorithm $(n=12)$. These included patients under CPR on arrival who underwent thoracotomy, and some with traumatic brain injury as the identified cause of their hypotension. The most common missing imaging was the FAST $(n=7)$.

\section{DISCUSSION}

Our institutional review revealed nine REBOA placements over the first year of use in our program, of which only one was placed as indicated based on our algorithm, and two additional placements indicated per the algorithm but with delayed placement in the OR. Thus, only $33.33 \%$ of REBOA placements were performed according to our institutional algorithm. In addition, multiple patients were identified who did not undergo REBOA placement despite meeting criteria for placement. A relatively high complication rate was noted, with four of the nine REBOA patients sustaining related complications.

The low compliance with our institutional algorithm has several potential explanations. First, individual trauma surgeons have varied practices with regards to the management of the hypotensive trauma patient, and surgeons with prior REBOA experience may be more likely to choose this intervention. Two patients had REBOA placed despite not meeting algorithm indications as they were never hypotensive; however, these 


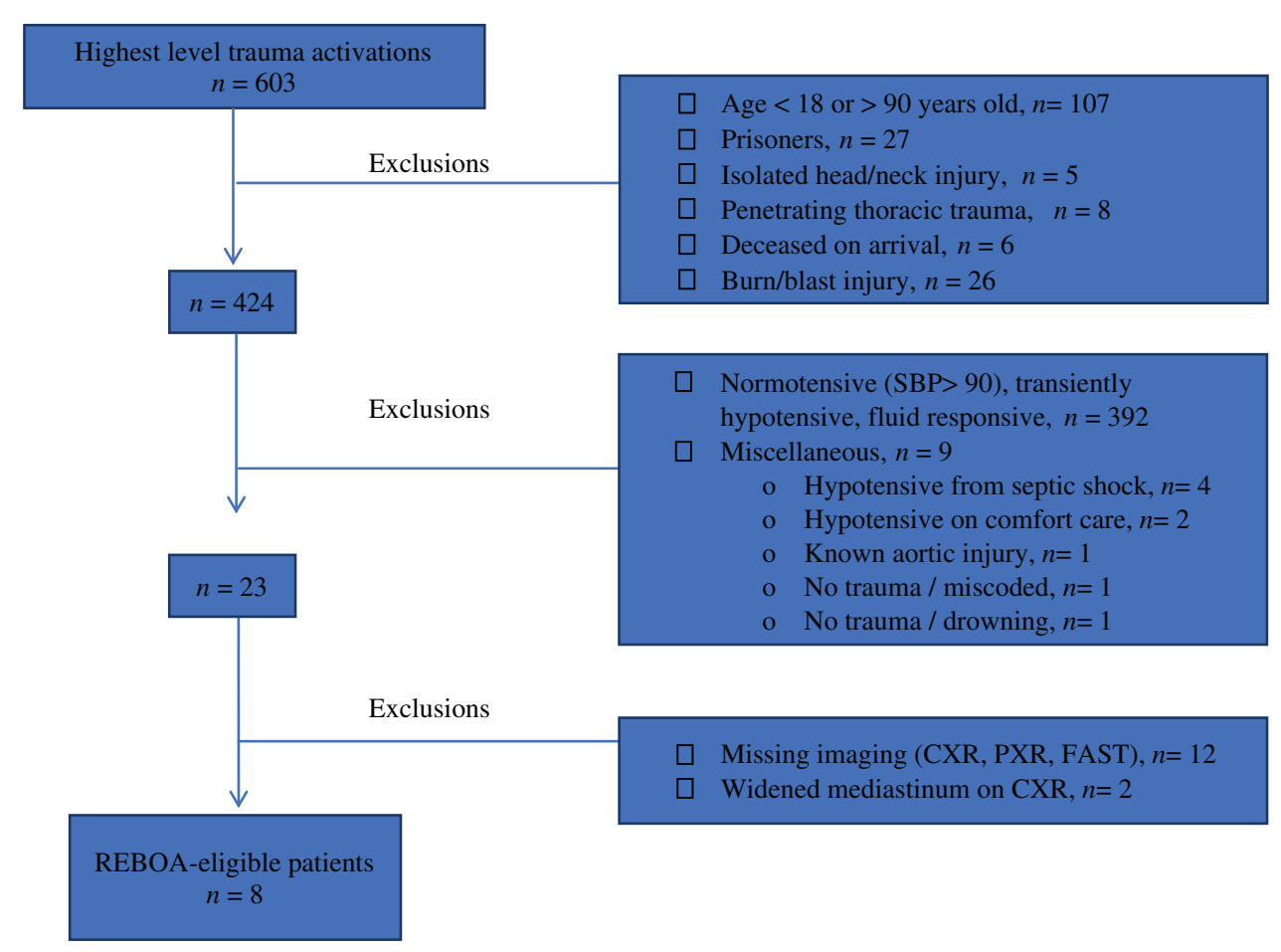

Figure 2 Breakdown of determination of REBOA-eligible patients.

were placed due to intraoperative hemorrhage and previous research has found that intraoperative REBOA placements are more likely to occur in patients with stable initial hemodynamics [17]. Two patients had REBOA placed despite widened mediastinum on CXR. In one patient, there was a known aortic injury and the REBOA was intentionally placed and inflated proximal to the injury. In the second patient, despite abnormal CXR, subsequent computed tomography of the chest did not reveal any signs of thoracic great vessel injury. Widened mediastinum has been found to have a poor predictive value for aortic injury [18] and our institutional algorithm is being redesigned to reflect this. Lastly, two patients had REBOA placed while under CPR, and could not be evaluated by our algorithm. These patients represent a unique subset of patients, and the optimal approach to hemorrhage control is not yet known; however, several studies have supported the use of REBOA in traumatic arrest [19,20]. When considering the REBOA-eligible patients who did not undergo REBOA placement in our cohort, $100 \%$ of these patients were taken straight to the OR from the ED for exploratory laparotomy. Thus, it is likely that the trauma surgeon in these cases thought the most expeditious method of hemorrhage control was via urgent surgical exploration. Ultimately, an algorithm can be used to guide decision making, but cannot replace clinical judgment.

Our complication rate was significantly higher than that reported in other studies, with one systematic review of 414 patients reporting a $5 \%$ rate of access-related complications [21]. As we are reporting a very small case series of nine patients at the start of implementation of a REBOA program, it is not surprising that our complication rate is higher than that reported in large series in the literature. As a result of the complications noted in this series, we have formalized our REBOA protocol to include mandatory vascular surgery consultation for the detection and management of potential REBOA-related injuries and the consideration of an on-table angiogram prior to sheath removal. We have additionally instituted mandatory tracking of REBOA cases and complications, with discussion at multidisciplinary QI sessions. These sessions have identified difficulties we have encountered in the implementation of a REBOA program including determining kit contents, kit location, and restocking to ensure multiple kits are routinely available. The kit has been standardized to include a 7 French introducer sheath, which is associated with lower rates of access-site complications [22]. In reviewing the complications, we have noted areas for education for staff involved, including reviewing our institutional algorithm, the steps of REBOA placement, and post-placement management. Training sessions are held as needed for nursing staff, OR staff, ED staff, and resident physicians.

REBOA is an emerging intervention for the patient in hemorrhagic shock and indications are evolving. Trauma and vascular surgeons [1-10], emergency physicians $[23,24]$ and pre-hospital providers [25,26] are using REBOA with increasing frequency. It is being deployed 
in both trauma patients as well as those with intraabdominal hemorrhage of non-traumatic etiology [27-32]. Although the technical process of placing a REBOA catheter in a patient is straightforward, multiple factors must be in place to ensure a given institution is well-equipped to best utilize the technology. Several key focus areas that must be addressed to ensure successful REBOA implementation were identified as a result of a rigorous QI process.

Training of all members of the surgical and ED teams is paramount to instituting a successful REBOA program. There are a number of formal courses available for training, but our data suggest that simply participating in a REBOA training course is not sufficient, as we found a number of missed opportunities for REBOA in our study. There must be ongoing training opportunities, refresher courses, and in-depth quality improvement processes to ensure continual improvement. In addition, complications occur as a result of REBOA use, and coordination with vascular surgery is necessary for aid in diagnosis and treatment of these. Our recommendations for successful REBOA program implementation are as follows (Table 7):

\section{Surgical Staff}

Technical training courses for trauma staff are the first step. Multiple options are available, including the BEST course, ASSET, and EVTM workshops. Residents and fellows should be included in these sessions. Multiple modes of access should be emphasized, including percutaneous by landmarks, ultrasound, and via cut-down. Success depends on procedural competency and on operator facility with the items in the REBOA kit and their limitations. REBOA placement difficulties should be reviewed on a frequent basis at departmental QI meetings.

Table 7 Recommendations for REBOA program implementation.

\begin{tabular}{ll}
\hline $\begin{array}{l}\text { Surgeons and } \\
\text { emergency } \\
\text { physicians }\end{array}$ & $\begin{array}{l}\text { Training of physicians in the placement of } \\
\text { the device }\end{array}$ \\
& $\begin{array}{l}\text { Familiarity with equipment, technique, } \\
\text { algorithm, and indications } \\
\text { Percutaneous access vs. femoral cut down } \\
\text { training }\end{array}$ \\
Tursing staff & Kraining to assist in procedure \\
& Content identification \\
Systems & Kocation of replacement items \\
Follow-up & restontents, location, availability, and \\
& Early vascular surgery involvement \\
& Post-operative imaging \\
& Multidisciplinary complication management
\end{tabular}

\section{Emergency Department Staff}

ED physicians, depending on the hospital, are present and assist in a variety of ways in the initial care of traumatically injured patients. ED physicians should be invited to in-house training sessions organized by the surgery department and QI sessions related to REBOA outcomes. Members of the ED staff must be familiar with the process for REBOA placement and are key partners in the successful rescue of these patients.

\section{Nursing Staff}

Individual training sessions should be held with ED and OR nursing and ancillary staff. The devices and the steps for placement should be reviewed. The OR nursing leadership for trauma may aid in educating staff on the equipment location and backup supplies if an item breaks or is missing.

\section{Systems}

REBOA kits have gone through various iterations since the device was created. We worked with the hospital purchasing and supplies department to arrange for kit procurement. Necessary equipment that was not part of the kits were identified to create more robust REBOA kits. Processes must be in place to re-stock kits. They must be easily accessible in both the OR and the ED, and potentially the intensive care unit.

\section{Follow-up}

The care of REBOA patients does not stop with balloon deflation. The trauma teams caring for the patients must be aware of post-REBOA complications such as thrombosis, arteriovenous fistula formation, limb ischemia, vascular injury, and spinal cord injury from ischemic time. The authors' practice pattern is to involve vascular surgery early in the care of these patients, for both management of complications and post-procedural angiograms before sheath removal. Protocols should be created to ensure patients receive appropriate imaging post-REBOA. All REBOA cases should be reviewed as part of departmental and hospital QI sessions. In particular in the beginning of implementing a REBOA program, trauma cases should be reviewed to identify patients who may have benefitted from the use of REBOA and algorithms should be modified as necessary to ensure the best care is provided to future patients.

\section{Limitations}

Our study is a single-center retrospective study of a level one trauma center and our findings may not apply to other health care systems. However, given the rising number of both trauma centers and non-trauma centers 
using REBOA for various indications, we hope our experience and hard-learned lessons will pave a smoother road for new adopters.

\section{CONCLUSION}

Successful REBOA use requires more than simply teaching surgeons the indications and techniques. To successfully adopt a REBOA program, there are many systemwide factors that must be addressed. System processes must be in place to ensure the equipment and procedures are standardized and familiar to all involved. Complications should be expected [33].

\section{Ethics Statement}

(1) All the authors mentioned in the manuscript have agreed to authorship, read and approved the manuscript, and given consent for submission and subsequent publication of the manuscript.

(2) The authors declare that they have read and abided by the JEVTM statement of ethical standards including rules of informed consent and ethical committee approval as stated in the article.

\section{Conflicts of Interest}

The authors declare that they have no conflicts of interest

\section{Funding}

The project described was supported by the National Center for Advancing Translational Sciences, National Institutes of Health, through grant number UL1 TR001860 for author CT. The content is solely the responsibility of the authors and does not necessarily represent the official views of the NIH.

\section{Author Contributions}

CMT, JJD, and JMG were responsible for study conception and design. CMT performed data acquisition. CMT, ESS, and JMG performed data analysis and interpretation. CMT, ESS, and JJD, JMG drafted the manuscript and were involved in critical revision of the manuscript.

\section{REFERENCES}

[1] Chang R, Fox EE, Greene TJ, et al. Multicenter retrospective study of noncompressible torso hemorrhage: anatomic locations of bleeding and comparison of endovascular versus open approach. J Trauma Acute Care Surg. 2017;83(1):11-18.

[2] Qasim Z, Brenner M, Menaker J, Scalea T. Resuscitative endovascular balloon occlusion of the aorta. Resuscitation. 2015;96:275-9.
[3] Aso S, Matsui H, Fushimi K, Yasunaga H. Resuscitative endovascular balloon occlusion of the aorta or resuscitative thoracotomy with aortic clamping for noncompressible torso hemorrhage: a retrospective nationwide study. J Trauma Acute Care Surg. 2017;82(5):910-14.

[4] Moore LJ, Brenner M, Kozar RA, et al. Implementation of resuscitative endovascular balloon occlusion of the aorta as an alternative to resuscitative thoracotomy for noncompressible truncal hemorrhage. J Trauma Acute Care Surg. 2015;79(4):523-30.

[5] Brenner M, Teeter W, Hoehn M, et al. Use of resuscitative endovascular balloon occlusion of the aorta for proximal aortic control in patients with severe hemorrhage and arrest. JAMA Surg. 2018;153(2):130-135.

[6] Dubose JJ, Scalea TM, Brenner M, et al. The AAST prospective Aortic Occlusion for Resuscitation in Trauma and Acute Care Surgery (AORTA) registry: data on contemporary utilization and outcomes of aortic occlusion and resuscitative balloon occlusion of the aorta (REBOA). J Trauma Acute Care Surg. 2016;81(3): 409-19.

[7] Moore LJ, Martin CD, Harvin JA, Wade CE, Holcomb JB. Resuscitative endovascular balloon occlusion of the aorta for control of noncompressible truncal hemorrhage in the abdomen and pelvis. Am J Surg. 2016;212(6):1222-30.

[8] Brenner ML, Moore LJ, Dubose JJ, et al. A clinical series of resuscitative endovascular balloon occlusion of the aorta for hemorrhage control and resuscitation. J Trauma Acute Care Surg. 2013;75(3):506-11.

[9] Biffl WL, Fox CJ, Moore EE. The role of REBOA in the control of exsanguinating torso hemorrhage. J Trauma Acute Care Surg. 2015;78(5):1054-8.

[10] Brenner M. REBOA and catheter-based technology in trauma. J Trauma Acute Care Surg. 2015;79(1):174-5.

[11] Villamaria CY, Eliason JL, Napolitano LM, Stansfield RB, Spencer JR, Rasmussen TE. Endovascular Skills for Trauma and Resuscitative Surgery (ESTARS) course: curriculum development, content validation, and program assessment. J Trauma Acute Care Surg. 2014;76(4):929-35.

[12] Brenner M, Hoehn M, Pasley J, Dubose J, Stein D, Scalea T. Basic endovascular skills for trauma course: bridging the gap between endovascular techniques and the acute care surgeon. J Trauma Acute Care Surg. 2014;77(2):286-91.

[13] Zakaluzny SA, Beldowicz BC, Salcedo ES, Dubose JJ, Moore LJ, Brenner M. Guidelines for a system-wide multidisciplinary approach to institutional resuscitative endovascular balloon occlusion of the aorta implementation. J Trauma Acute Care Surg. 2019;86(2):337-43.

[14] Galante JM. Early adoption of resuscitative endovascular balloon occlusion of the aorta: the beginning of a journey. JAMA Surg. 2018;153(2):136.

[15] Darrabie MD, Croft CA, Brakenridge SC, et al. Resuscitative endovascular balloon occlusion of the aorta: implementation and preliminary results at an academic level I trauma center. J Am Coll Surg. 2018;227(1):127-33.

[16] Johnson MA, Williams TK, Ferencz SE, et al. The effect of resuscitative endovascular balloon occlusion of the aorta, partial aortic occlusion and aggressive blood transfusion on traumatic brain injury in a swine multiple 
injuries model. J Trauma Acute Care Surg. 2017;83(1):61-70.

[17] Vella MA, Dumas RP, DuBose J, et al. Intraoperative REBOA: an analysis of the American Association for the Surgery of Trauma AORTA registry. Trauma Surg Acute Care Open. 2019;4(1):e000340.

[18] Vasileiou G, Qian S, Al-Ghamdi H, et al. Blunt trauma: what is behind the widened mediastinum on chest X-ray (CXR)?. J Surg Res. 2019;243:23-6.

[19] Teeter W, Romagnoli A, Wasicek P, et al. Resuscitative endovascular balloon occlusion of the aorta improves cardiac compression fraction versus resuscitative thoracotomy in patients in traumatic arrest. Ann Emerg Med. 2018;72(4):354-60.

[20] Wasicek PJ, Yang S, Teeter WA, et al. Traumatic cardiac arrest and resuscitative endovascular balloon occlusion of the aorta (REBOA): a preliminary analysis utilizing high fidelity invasive blood pressure recording and videography. Eur J Trauma Emerg Surg. 2019;45(6):1097-105.

[21] Manzano-Nunez R, Orlas CP, Herrera-Escobar JP, et al. A meta-analysis of the incidence of complications associated with groin access after the use of resuscitative endovascular balloon occlusion of the aorta in trauma patients. J Trauma Acute Care Surg. 2018;85(3):626-34.

[22] Teeter WA, Matsumoto J, Idoguchi K, et al. Smaller introducer sheaths for REBOA may be associated with fewer complications. J Trauma Acute Care Surg. 2016;81(6):1039-45.

[23] Brenner M, Bulger EM, Perina DG, et al. Joint statement from the American College of Surgeons Committee on Trauma (ACS COT) and the American College of Emergency Physicians (ACEP) regarding the clinical use of resuscitative endovascular balloon occlusion of the aorta (REBOA). Trauma Surg Acute Care Open. 2018;3(1):e000154.

[24] Sato R, Kuriyama A, Takaesu R, et al. Resuscitative endovascular balloon occlusion of the aorta performed by emergency physicians for traumatic hemorrhagic shock: a case series from Japanese emergency rooms. Crit Care. 2018;22(1):103.

[25] Sadek S, Lockey DJ, Lendrum RA, Perkins Z, Price J, Davies GE. Resuscitative endovascular balloon occlusion of the aorta (REBOA) in the pre-hospital setting: an additional resuscitation option for uncontrolled catastrophic haemorrhage. Resuscitation. 2016;107:135-8.

[26] De schoutheete JC, Fourneau I, Waroquier F, et al. Three cases of resuscitative endovascular balloon occlusion of the aorta (REBOA) in austere pre-hospital environment-technical and methodological aspects. World J Emerg Surg. 2018;13:54.

[27] Lendrum R, Perkins Z, Chana M, et al. Pre-hospital resuscitative endovascular balloon occlusion of the aorta (REBOA) for exsanguinating pelvic haemorrhage. Resuscitation. 2019;135:6-13.

[28] Russo RM, Girda E, Kennedy V, Humphries MD. Two lives, one REBOA: hemorrhage control for urgent cesarean hysterectomy in a Jehovah's Witness with placenta percreta. J Trauma Acute Care Surg. 2017; 83(3):551-3.

[29] Manzano-nunez R, Escobar-vidarte MF, Naranjo MP, et al. Expanding the field of acute care surgery: a systematic review of the use of resuscitative endovascular balloon occlusion of the aorta (REBOA) in cases of morbidly adherent placenta. Eur J Trauma Emerg Surg. 2018;44(4):519-26.

[30] Okada A, Nakamoto O, Komori M, Arimoto H, Rinka H, Nakamura H. Resuscitative endovascular balloon occlusion of the aorta as an adjunct for hemorrhagic shock due to uterine rupture: a case report. Clin Case Rep. 2017;5(10):1565-8.

[31] Ordoñez CA, Manzano-nunez R, Parra MW, et al. Prophylactic use of resuscitative endovascular balloon occlusion of the aorta in women with abnormal placentation: a systematic review, meta-analysis, and case series. J Trauma Acute Care Surg. 2018;84(5):809-18.

[32] Manzano-nunez R, Escobar-vidarte MF, Orlas CP, et al. Resuscitative endovascular balloon occlusion of the aorta deployed by acute care surgeons in patients with morbidly adherent placenta: a feasible solution for two lives in peril. World J Emerg Surg. 2018;13:44.

[33] Davidson AJ, Russo RM, Reva VA, et al. The pitfalls of resuscitative endovascular balloon occlusion of the aorta: risk factors and mitigation strategies. J Trauma Acute Care Surg. 2018;84(1):192-202. 